\title{
1 \\ Ambiguous embodiment and organ transplantation
}

Recipients of cadaver organs, like those with organs from living relatives, often express the sentiment that one can acquire the donor's emotional, moral, or physical characteristics. Such qualities can be elaborate and imaginative, especially when the donor was an anonymous stranger. Some patients live in fear of the independent or animate qualities of the new organs.

(Sharp, 1995: 372)

\section{Introduction}

This first chapter aims to offer an introduction to the stories told by organ transplant recipients that relate to how they experienced a subjectivity ${ }^{1}$ alteration post-transplant. Clinical organ transplantation between human beings has been done for the last 50 years and is no longer the experimental treatment that it once was. Organ transplantation depends on a view of human bodies being machine-like and forming a separate container for the self, perhaps akin to an individual driving a car. Although this body-as-machine view is relied upon by medical professionals and is one that medical procedures such as organ transplantation are dependent upon, the persistence of alternative stories of bodies and organs suggest a more complex relationship exists between a person and the body.

As I shall outline below, narratives of subjectivity alteration can be found in interviews as far back to the first heart transplant Louis Washkansky underwent in the late 1960s. Such narratives persist decades later, for example, in a book written by Claire Sylvia (1997) called A Change of Heart: The Extraordinary Story of a Man's Heart in a Woman's Body. She details the subjectivity alterations 
she experienced after receiving an organ from a young boy called Tim: changes that were experienced by her before knowing anything about the donor and yet which coincided with the donor characteristics.

It is difficult to ascertain how many organ transplant recipients report some form of subjectivity change and certainly not every transplant recipient does. Nevertheless, even if it is not a widespread phenomenon, it is an entrenched one. It is not my intention to challenge whether these stories are true or not. On the contrary, I think these narratives are important and I wish to explore what subjectivity alteration tells us about how individuals experience embodiment. That is, whether an individual has a body which they are separate from as the body-as-machine model suggests, or whether a person experiences embodiment as being a body and there is no separation. Or indeed whether the experience of embodiment is ambiguous, variable and fluid, affected by events occurring in the body, and the environment outside it.

Through a review of social science research conducted with organ transplantation recipients, it is shown that the identity changes most frequently mentioned are an alteration in gender or age, or preferences for food or music. Medical and social science communities have long sought to offer explanations for these stories, and these relate to social theories about contagion and contamination and biological explanations about the existence of cellular memory. These explanations differ in explaining how the characteristics are transferred (whether it is biological and cellular or social contamination). I suggest that because donated organs come from another human being, there is a shared understanding of what it is to be a human being that is universal, but being a human can be a particular version of this universality. There are a variety of ways of being human, so this generates many different characteristics about the person who donated the organs and the origin of human organs; for example, they came from an individual who was a certain age or gender, to a preference for particular foods. Narratives such as these relating to the universality but the individuality of the human organs suggest the organ is not a culturally or socially neutral entity in the same way as an implantable device might be (as I go on to discuss later in Chapter 4). 
In this chapter, I outline the narratives of organ transplant recipients, that tell of how receiving an organ changes who they are and alters their subjectivity. The donated organ is, in some way, rehumanised or socialised with the donor's presence (Fox and Swazey, 1992). This challenges a Cartesian Dualism ideology that suggests the body and the person are separate and distinct entities. Turning towards a more phenomenological approach originating from Merleau-Ponty (2012, 1945), and later by Leder (1990), I compare accounts of subjectivity alteration in transplantation and amputation to delve further into what happens to identity when modifications are made to the body a person was first born with. Organ transplant recipients can gain a new identity whereas amputating limbs is synonymous with an identity loss - the first procedure occurs inside the human body and is an invisible gain, whereas the latter is a visible loss. I introduce the concept of the 'Triad of I' to highlight just how important the integrity of the human body is, both to identity and body image. I show how assumptions are made about the biological characteristics of the donated organs based on the donor's gender identity. The donated organ is considered to be coterminous with the gender of the donor, despite the organs not being visible.

I begin, however, with the history of organ transplantation as a procedure, and then I turn to a thoroughgoing review of what 'organs with history' can say about how the body and its organs are experienced.

\section{Inner space and outer face}

Of any transplant that would entail an alteration of a person's subjectivity or identity, a face transplant would appear to the most challenging for the recipient. The recipient's face will become a hybrid of both their face and that of the donor and not a true reflection of either. For the recipient, however, the donated face is a constant and visible reminder that the facial modification is a visible alteration in identity. Isabelle Dinoire received the first face transplant in $2005 .^{2}$ She reported that the face transplant had been challenging to cope with due to several cases of 
rejection caused by the ability of a human body's immune system to attack that which is perceived as foreign. As she also outlines in her book Le Baiser d'Isabelle, there was also the strange sensation of accepting the inside of 'someone else's mouth. It was odd to touch, to touch it with my tongue. It was soft. It was horrible' (quoted in The Guardian 2007). ${ }^{3}$ There are many arguments around the ethics, cost, and long-term health implications of a non-life-saving procedure such as facial transplantation, the perceived vulnerability of the patients, a lack of donor anonymity, patient compliance and the effect on the recipient's social circle and so on. A key concern relates to the way that the face reflects personal identity:

As an expressive part of our body, it represents identity in a way no other part of the body does. It is the most intimate, the most individual characteristic of our body. It is what we recognise as ourselves and what others recognise as us.

(Freeman and Abou Jaoude, 2007: 76)

The question that drove much of the debate in the first face transplant appeared to be about whether or not transplantation had gone too far in altering the identity of the person (TaylorAlexander, 2004, Freeman and Abou Jaoude, 2007, Le Breton, 2015, Theodorakopoulou et al., 2017, Martindale and Fisher, 2019). However, similar concerns about identity were raised when the first heart transplant was conducted almost 40 years previously. If the face is the image of identity, then the heart is the internal site of identity, as it is an organ culturally most closely associated with the intangible aspects of what emotions, soul and personhood are. Therefore, as I turn to next, transplanting the heart might also be thought to have profound consequences for a person's identity.

\section{The first heart transplant}

It is 3 December 1967. The South African heart surgeon, Christiaan Barnard (1922-2001) has just conducted the world's first heart transplant. He did so by removing the heart from 25 -year-old Denise 
Darvall who had died in a car accident and placing it into the body of grocer Louis Washkansky. Louis, perhaps like others before him who are the 'first' in experimental procedures, died only 18 days later. His death from pneumonia was a result of complications due to the suppressing of his immune system to stop the body attacking Darvall's heart (Høystad, 2007). ${ }^{4}$ Until advances in immunosuppression were made, organ transplantation procedures remained unsuccessful. The media storm that ensued after the first heart transplant was not because Louis had died. Nor indeed, whether in South Africa, the apartheid system would create a situation whereby one section of the population would become a source for another (Bound Alberti, 2010). Instead, journalists asked Louis how it felt to have a female heart or one that was not Jewish (Nathoo, 2007: 163). There were questions raised about the consequences of 'changing a soul' (Bound Alberti, 2010) because:

for the first time one of the most important metaphors for personhood had been cut out, handled and cleaned and then placed inside the body of another individual. In a few historic moments, the borders of one human body had been breached by the symbolic core of another.

(Helman, 1991: 6)

The heart has a symbolic and cultural association with identity, affectivity, feelings and emotions. 'To have a heart to heart', to 'love someone from the bottom of my heart', 'he found it in his heart', 'to pull on your heartstrings' and 'her heart is in the right place' are all common expressions of how the heart is the emotional base of human beings, the force that is required to be humane. The symbolic heart is associated with what we know as 'being human' as emphasised by the Tin-man's plea for a heart in the The Wizard of $\mathrm{O} z$ (1939). Indeed in The History of the Heart Høystad writes how the heart 'has also been made the seat of our conscience, since bad conscience is experienced as a stab or sudden pain in the heart. For that reason, the soul is placed in the heart' (Høystad, 2007: 12). The heart as a pump located in the body-as-machine has, it should be noted, an overtly strong masculine image associated with it (Emslie and Hunt, 2009), whereas the symbolic image associated with it is feminine. The heart sits awkwardly in the medical and scientific ideology of the Cartesian body-as-machine, as the 'pump 
or the engine for the body' while simultaneously remaining in its metaphoric space, 'symbolising the conjunction of body and soul' (Manning Stevens, 1997: 276). The heart sits uneasily in a place that views it in medical terms, like a pump or an engine in the mechanical body, but also has a symbolic and cultural association with identity, affectivity, feelings and emotions.

\section{I'm just a broken machine?}

For Louis' wife, there was an initial concern that the heart transplant had somehow changed Louis. In documentary footage shown later:

It started with 'The Man with the Golden Hands,' which is how Louis Washkansky, chatting in Yiddish to his wife, describes Christiaan Barnard who performed the world's first heart transplant on Louis. He died a couple of weeks later ... At first Louis seemed to be doing wonderfully well. She was not allowed to see him until three days after the operation ... 'I was very apprehensive because I thought his personality might have changed, not realising that it is the brain that makes the person. I was happy to see he was the same Louis'.

('A Knife to the Heart', BBC 1 Documentary, 31 April 1996

www.bbcactivevideoforlearning.com/1/Search. aspx ?PageIndex $=0 \&$ SeriesID $=833$, emphasis added )

Clinicians reassured her that Louis was still the same, as it was the 'brain that makes the person'. However, months before Louis' transplant, changes to personal identity through the transplantation of organs was a source of concern for the anthropologist Edward Leach in his BBC Reith Lecture address in 1967:

The marvels of modern technology fill us with amazement but also with dread. It was alright when the surgeons just fitted us up with artificial arms and legs, but now there are people going round with plastic guts, battery-controlled hearts (pacemakers), dead man's [sic] eyes and twin brother kidneys, there begins to be a serious problem of self-identification ... Am I just a machine and nothing more?

(Quoted in Nathoo, 2007: 161)

Indeed, we can all ask 'Am I just a machine or nothing more?' If I am 'more', what kind of more is it? Descartes' (1641) view was 
that the body is a machine and nothing more. The 'self' therefore is one way of discussing the internal cognitive processes of an individual. In the modern Cartesian version of the relationship that a self has with its body, an analogy can be drawn between medical modifications to the body and, for example, repairs on a vehicle. The Cartesian construction of the body is one of an empty vehicle animated by the brain as the material manifestation of the self which is the driver. The vehicle, or the individual's body, is taken to a garage for repairs carried out by the 'mechanics of medical science' (Helman, 1991) if it breaks down or needs parts replaced. The medical mechanics use recycled parts (e.g. organs) separated from other body vehicles. Such modifications are mediated by the expert medical systems, that determine whose body can be repaired, replaced or possibly regenerated next, dependent on prognosis and available resources. Descartes viewed the body and the self (or mind) as two distinct and separate entities based on his 'I think therefore I am' conclusion, beginning from a starting point that his senses cannot be trusted (Farr, Price and Jewitt, 2012). In the face of the doubt that the senses can produce, Descartes considered them highly unreliable sources of knowledge. Descartes argued that the only thing that he could be sure of, the only knowledge that could be relied upon, was 'je pense, donc je suis'. The only thing he could be sure of, therefore, is 'I think therefore I am', or in the Latin, 'cogito ergo sum'. There must be, he concluded, a thinking self to be thinking. This 'I', 'who thus thought, should be something', is separate from a body that is a vehicle for the intangible, non-material substance of cognition and the self. I am just a machine, nothing more or less. Transplant surgery depends on the idea of a body that has interchangeable parts. If one of the components fail, say a kidney, then it can be removed and another inserted in its place. In this view, then, the body is like a car. Surgeons are like mechanics. The parts are exchangeable (although most do not come with a guarantee or warranty). The Cartesian idea of a split between self and body has been highly influential in the biomedical world; the body has little relation to the self and is viewed as a vessel or vehicle like a car but nothing more. Having a body - a dualistic version of embodiment - implies there are no identity or relational issues that result from making an organic addition to the body. 


\section{The brain as self}

The legacy of the Cartesian ideology of having a body-as-machine, with a self that is materialised as brain and operationalised as thought, has had traction in most of the modern West, not only in that of the medical system. As Burkitt argues: '[I]n the Western world individuals have grown accustomed to a way of understanding themselves which divides their existence between the mind and the body' (Burkitt, 1999: 7). Elevated physiologically and epistemologically, the self is housed in the brain and is the driver of the Cartesian vehicle. In modern society, the thinking self is now closely associated with the brain as the materiality of self-identity and cognition. Indeed, the 1990s was declared the 'Decade of the Brain' and neurological explanations and research from neuroscientists arguing the mind is located in the brain increasingly gained influence. Vidal, in his article 'Brainhood, Anthropological Figure of Modernity' (2009), suggests it is only in the modern era that this idea of self, materialised in the brain, became accepted wisdom. His drawing upon data and events demonstrating, for example, the decline of an Aristotelian view of the soul as the animator of the body in the 17th century and the rise and fall of the humour theory of Galen, Vidal (Vidal, 2009) demonstrates how other historical factors led to the brain-centred version of the self. Experiments showed in the 1950s that people who have epilepsy could be treated while still conscious; that split-brain experimentation demonstrated how sensory information is sent to the opposite side of the brain when the two halves are separated. Along with the histological research on Einstein's brain, through to recent imaging technologies such as fMRI (Functional magnetic resonance imaging) that measures brain activity, this vast body of research showed that the search for the self, as Vidal shows, can be halted.

Then the search for the self that began with Descartes wondering 'where I am' has ended and the self is found in the brain. Localising the person in the brain - a neuro-reductionist explanation localises the self as the mind in the brain. The second aspect of neuro-reductionism, of reducing a person to neurological matter and processes, locates ' $I$ ' identity as neurological information and cognitive function. In the neurological view of the body, the brain rules supreme in the machine and has a body that is increasingly understood in Cartesian parts (Hacking, 2007: 78). 
The consequences of both the equation of self as brain and identity as neurological information is an increasing tendency to see a self as being brain as opposed to having a brain (Vidal, 2009). Indeed, it is an apparent fact that nowadays 'we are essentially our brains' (Glannon, 2009: 321). It appears self-evident (pun intended) that it is the brain where the self can be localised. Brain functioning is clearly crucial to a being as a person, yet being a person should not then be reduced, argues Vidal, to being a brain. However, this is what is occurring. Mind state, consciousness and, indeed, the thinking self is closely connected to brain state nowadays to the extent that the two are reducible to each other. The specific emphasis on the self as a cognitive process is also an experience that is common to most people. When I listen to my thoughts, like the ones I am having now when reading and writing this, I experience them as being located somewhere in my head. The philosopher and bioethicist Leon Kass, when thinking about where 'I' am in the body, suggested that I find my 'self' in the brain behind the eyes somewhere:

Science tells us the brain and no one would naturally give such an answer. Much of the time, I think, we feel ourselves concentrated just behind the eyes; When someone says 'look at me' we look at his [sic] face - usually the eyes, expecting there to encounter the person or at least his [sic] clearest self-manifestation.

(Kass, 1985: 23)

It is easily assumed that the self is located in or around the head. Terms commonly used in English language and conversation refer to this such as 'when you need your head examined' or questioning what was 'going on inside someone's head'. While I rewrite these words, I can hear them in my head before, and during, the writing of them. I have an awareness of mind and of myself thinking as well as writing. As human beings, cognition is experientially located in the head, and I would identify myself (or mind as the cognitive process of self) in the head area during my process of introspection, or reflection, similar to Kass. The brain is synonymous with cognition, mind and consciousness, essentially making the brain the most important location and site of the machine body. ${ }^{5}$ Recent moves to mindfulness are based on a cognitive way of reconnection: it 
is a way of becoming reconnected and of 'waking up to what's happening inside of you and in the world, moment by moment' (Williams and Penman, 2014: 39).

Mrs Washkansky's concern about her husband undergoing some form of identity change through his clinical heart transplantation is assuaged when she realises that 'it is the brain that makes the person'. Her husband, after all, was the same Louis and replacing his heart had not changed him. The brain reigns supreme.

\section{Early anthropomorphisation}

In 1974, Fox and Swazey published their important book The Courage to Fail (Fox and Swazey, 1974) outlining the social and ethical dilemmas emerging with the new practice of clinical human organ transplantation. Indeed, this was a crucial turning point in transplant history. Although the procedure was still experimental, the effects and consequences it had had on donor families, recipients and health professionals involved, were now available to Fox and Swazey. In the United States, at the Harvard University Program on Technology and Society they had decided that organ transplantation was sufficiently advanced to allow them to study it in a way that was not deemed to be 'too futuristic or speculative' (Fox and Swazey, 1974: xxxiii).

In these early days, one of the issues that Fox and Swazey identified is what they term an 'anthropomorphization' of the donated organ by the recipients:

Many [recipients] still grapple with the unrequitable magnitude of the gift received and with the haunting sense that some of the psychic and social as well as the physical qualities of the donor are transferred with his or her organ into their body, personhood and life.

In this early social science research, one organ transplant recipient suggests to them: 'I had a strong feeling that I had a part of another man's body; a man that I didn't even know' (1974: 31). Other research continued to marshal together accounts of how incorporating an organ affected the recipient's identity. Simmons, Klein and Simmons' (1987) review of several studies in the early 1970s 
suggested ethnicity, youth and gender were all characteristics thought to have been transferred from the donor:

many investigators have described cases in which the recipient had difficulty incorporating the donor organ into his [sic] body image (Abram, 1972; Cramond 1967; Kemph 1966). Abram (1972) reports a case in which a white Ku Klux Klan member became active in the NAACP [National Association for the Advancement of Colored People] after receiving a kidney from a black cadaver; Viederman (1974) tells of a black man who fantasized that his kidney from a white donor was attacking him. A heart transplant patient was reportedly haunted by a hallucination in which the cadaver donor returned for her heart (Castelnuovo-Tedesco, 1973; Lunde 1969). Some males have felt feminized by organs from female donors (Castelnuovo-Tedesco, 1973; Viederman, 1974). A brother acted as if his masculinity was threatened when he discovered that his donor brother was a homosexual (Lefebvre, 1973). Viederman (1974) concludes that if the related donor is not liked, the kidney becomes a hostile 'introject' and chances for rejection are enhanced (Simmons et al., 1987: 67).

In this review quoted above, an incident of a biological rejection is not caused by the recipient's immune system but through a social rejection of the donor's organ. Years later, a similar social rejection was experienced by Clint Hallam, who had received the world's first single hand transplant. The hand was subsequently amputated years later as he was said to have rejected the hand due to his inability to accept as his own (Slatman and Widdershoven, 2010). Attention is immediately drawn, therefore, to the importance of incorporating another organ or limb as an accepted and legitimate part of the recipient's identity.

\section{Later hearts}

Biomedical practices and advances in transplantation are testing the limits of the Cartesian model of separation and duality. More recently, research conducted by Shildrick (Shildrick, 2010, Shildrick, 2015) suggests that very few of the 30 heart recipients in her study were able to view the heart as a 'transferable and disembodied organ that has shed all vestiges of its prior location ... 
aware that their sutured bodies spoke to a different mode of beingin-the-world' (Shildrick, 2010: 18). Drawing on a 'birthing-inreverse' analogy, Shildrick and her colleagues suggest that just as a pregnant woman needs to acclimatise to being pregnant and living with an additional self in the form of a growing baby, so an organ transplant recipient requires time to become at ease with a foreign addition; in this case an organ and not a baby. Shildrick's research suggests that nearly all of her recipients suffered a general sense of unease post heart transplant and that recipients are challenged by the 'persistence of the other' as well as the 'cultural baggage' associated with the heart insofar as it is seen as the biological and metaphorical seat of life (Shildrick, 2015). In this understanding, organs 'are always more than mere things' (Lock, 1995b), and the heart is the symbolic centre for the emotions that make human beings human. Early studies have found that some donor families donate partly due to a desire to give some form of an 'immortality' to the deceased; this is gained through allowing the donated organ to 'live on' in the recipient (Fulton, Fulton and Simmons, 1987). In one mother's words:

I think we generally got approval from most people but kind of like, 'Isn't that nice of her to do this?' I didn't do it because I thought it was nice to do. I did it because I thought [crying], I guess, something to help him [son]. Perhaps he was alive as far as I was concerned. So his death wasn't totally a death.

(Fulton, Fulton and Simmons, 1987: 352)

'Perhaps he was alive ... his death wasn't totally a death' is based on a desire to make some form of life from death, a reasoning that within the recipient's body, there was a 'living on' of the person. Similarly, a donor father suggested: 'Well, it's a funny feeling. In a sense you think they're still around and yet they're not. [As long as his kidneys still function] he isn't dead down there' (Fulton, Fulton and Simmons, 1987: 352). Then for some donor families, there is a sense that organ donation is more than exchanging one body part for another. ${ }^{6}$ Reported subjectivity alterations are not only found to be associated with organs from deceased donors. Research with living donors who donated a kidney or part of a liver show that a quarter of those participating in the study $(n=111)$ referred to what the authors term 'identity mergers': 
Recipient (brother is the donor): We joke about becoming the same person. Being myself more active than he is, he says I got the better kidney. All kinds of jokes - basically, he says, that I'm younger that he is, though I'm older, that I got the better kidney. I look younger, I'm more active.

(Simmons, Klein and Simmons, 1987: 68)

Furthermore, despite the cultural and social symbolism associated with the heart, as reviewed earlier in this chapter, it is not the only transplant that can cause the recipient to report some subjectivity alterations. Other transplantable organs such as lungs and kidney could also affect similar alterations (Sanner, 2001b). In Sharp's (1995) ethnography of 26 recipients, she suggests the integration of an organ such as a lung could result in a generic 'transformative experience'. The majority of her recipients stated that they had experienced a 'new lease of life', leading Sharp to conclude that organ transplantation is a transformative experience. One recipient of a lung transplant told her:

I wasn't myself before - you get into your own little world. I couldn't wash my hair, eat or even talk without losing my breath. My brain didn't get enough oxygen so I couldn't think straight.

(Sharp, 1995: 372)

Feeling 'stronger and younger' may be ubiquitous to any patient after a life-saving operation. It is normal, if not desirable, that patients enjoy a significant increase in their quality of life (Lock, 1995a, Lock, 1995b, Sharp, 1995). Indeed, scholars suggest that for the recipients the alleged inheritance of personal characteristics stem from an altered physical and psychological state resulting only from regaining health and of feeling better and stronger (Bound Alberti, 2010). However, recipients of organ transplantation experience negative transformations and emotions post-transplant, for example, a sense of anxiety as well as an identity crisis:

I experienced attacks of anxiety, fear of death ... I ran out in the corridors totally wrecked. I couldn't find me. Who am I? Where do I come from? I was completely dizzy. It was like the familiar me but the safety I had felt was no longer there. Instead there was a new person.

(Forsberg, Bäckman and Möller, 2000: 331) 
Indeed, Sharp found that 'some patients live in fear of the imagined independent or animate qualities of the new organs' (Sharp, 1995: 372).

\section{Making the strange familiar}

In the 1970s, and a practice that carries on in the UK today, authors argued that any information exchanged between donor and recipient was unnecessary and of limited benefit (CastelnuovoTedesco, 1973). Fox and Swazey argue that the anonymity inherent to deceased organ donation, at least in the early days, eases any guilt that the recipient and their family might have from benefiting from the donor's death (in the case of deceased donation). It also limits the recipient's knowledge of the donor's life and this, they say, 'insulates the recipient and his [sic] family from being influenced by their knowledge of the donor's person, character, social background or life history' (1974: 32). Later in 1992, Fox and Swazey continued to argue anonymity is about protecting parties 'from close encounters with the animistic, magic-infused thinking about transplanted organs in which the givers and receivers of cadaver organs often engage' (Fox and Swazey, 1992: 43). The 'animistic' thinking referred to are the narratives about how the transplanted organ is imbued with the characteristics of the donor, resulting in recipients experiencing a change from improving health as well as an alteration of self.

From the 1970s to the present day in the UK, transplant coordinators gate-keep the information that recipients and deceased donor families learn about each other. The UK's NHS Blood and Transplant have stated that: '[P] rotecting the anonymity of both the donor and the transplant recipient is of paramount importance. ${ }^{7}$ In the UK, donor families and recipients receive minimal information about each other, perhaps just age and gender, but no additional information immediately after the donation, such as ethnicity or place of donation. Letters may be exchanged after a period has passed. Eventually, and if the donor family and the recipient want to meet, this can be facilitated by a transplant co-ordinator. 
To demonstrate that information about the donor is irrelevant in affecting the type of subjectivity alteration reported however, research has attempted to match the changes that are said to occur in the recipient with unknown characteristics of the donor (Pearsall, Schwartz and Russek, 2002). Pearsall, Schwartz and Russek argue that 'sensitive' transplant recipients can experience 'changes in food, music, art, sexual, recreational and career preferences, as well as specific instances of perceptions of names and sensory experiences related to donor' (Pearsall, Schwartz and Russek, 2002: 191). In the interviews they carried out with ten organ transplant recipients, as well as their friends or family members and also the donor family, despite the small number taking part in the research, Pearsall draws out the similarities in stories between the donor families and the recipients:

Organ Recipient: If you promise you won't tell anyone my name, I'll tell you what I've not told any of my doctors. Only my wife knows. I only knew that my donor was a 34-year-old, very healthy guy. A few weeks after I got my heart, I began to have dreams. I would see a flash of light right in my face and my face gets real, real hot. It actually burns. Just before that time, I would get a glimpse of Jesus. I've had these dreams and now daydreams since: Jesus and then a flash. That's the only thing I can say is something different, other than feeling really good for the first time in my life. $\cdots$

Deceased Organ Donor's Wife: What really bothers me, though, is when Casey said offhandedly that the only real side effect of Ben's surgery was flashes of light in his face. That's exactly how Carl died. The bastard shot him right in the face. The last thing he must have seen was a terrible flash. They never caught the guy, but they think they know who it is. I've seen the drawing of his face. The guy has long hair, deep eyes, a beard and this real calm look. He looks sort of like some of the pictures of Jesus.

(Pearsall, Schwartz and Russek, 2002: 202)

Another narrative suggests that the information that was eventually learned about the donor was contrary to the recipient's initial assumptions:

When a 47-year-old Caucasian foundry worker received the heart of a 17-year-old African-American student, he presumed that the donor would have preferred rap music. Hence, he dismissed the idea that 
his new radical change in preference for classical music could have come from the heart of the donor. However, unbeknownst to the recipient, the donor actually loved classical music and died 'hugging his violin case' on the way to his violin class.

Other stories told to Pearsall, Schwartz and Russek (2002) are about a woman who was terrified of heights until she was given the lungs of a mountain climber. Another case highlights how a sevenyear-old girl had nightmares about being killed after being given the heart of a child who had been murdered. A lawyer from Milwaukee received the heart of a 14-year-old boy and inherited his craving for Snickers and a man of 25 years of age received a woman's heart and, it is reported, to his girlfriend's delight developed a liking for shopping.

\section{How embodiment is embedded: gender in organ transplantation}

In Sharp's research, a participant told her that he had received jokes from colleagues after his kidney transplant: 'You might start peeing sitting down now that you have a lady's kidney! ... So, every day I assure them, nope, I'm still peeing standing up' (kidney recipient in Sharp, 1995: 372). In her autobiography, Claire Sylvia, one of the first recipients of a heart and lung transplant in the US, remarks at length on the challenges that incorporating a new male gender posed as her health improved:

Until the transplant, I had spent most of my adult life either in a relationship with a man or hoping to be in one. But after the operation, while I still felt attracted to men, I didn't feel that same need to have a boyfriend. I was freer and more independent than before - as if I had taken on a more masculine outlook. My personality was changing, too and becoming more masculine. I was more aggressive and assertive than I used to be and more confident as well. I felt tougher, fitter and I stopped getting colds. Even my walk became more manly [sic] ... A certain feminine tentativeness had fallen away. My sexual preferences didn't change in an overt way - I remained a confirmed heterosexual - but something had shifted deep within me.

(Sylvia and Novack, 1997: 107) 
This gendering of the organs is a finding regardless of whether the organ was from a living or deceased donor. A sister who donated to a brother is reported to have told him: 'Oh, one time I said something to him like: "If you get turned on when you walk past a man, blame it on me"' (Simmons, Klein and Simmons, 1987: 68). Interviews with organ transplant recipients conducted by Sanner showed some recipients, both male and female, welcoming male organ transplants as better and stronger as opposed to an organ from a female donor which might be considered more effeminate (2003: 394). Gender appears to be a key characteristic repeatedly brought up in stories of how organ transplantation led to a change in the recipient's subjectivity.

\section{Cellular and pharmacological explanations}

How can the characteristics of the donor, such as gender, be passed on to the recipient? Some commentators and health professionals doubt the veracity of the narrative of altered subjectivity and point to the personality effects resulting from taking immunosuppressants such as cyclosporine to dampen the immune system's response to reject the transplanted organ. It is essential that organ donor recipients take immunosuppressants to lower their immune response system, but it is also a medication known for side-effects such as developing sugar cravings. Other explanations suggest subjectivity alteration is related to the cell migration that occurs from the donor to the recipient. One of the surgical pioneers of organ transplantation argued in medical journals such as The Lancet that cell migration from the donor to the recipient is an essential part of the organ being accepted into the body and can be found throughout the recipient's body, with 'both the allograft and recipient become genetic composites' (Starzl et al., 1993). This idea of the recipient becoming a genetic composition of themselves and the donor is debated. The organ donor recipient will be a mix of two different types of DNA; however, it is counter-argued by some in the medical professsion that the donor DNA remains located at the site of the organ and does not circulate throughout the body. A related idea to the genetic composite one is that organs have a 'cellular memory' and that 
this is the cause of the subjectivity alteration experienced by the recipient. Indeed, it is one explanation offered by an organ transplant recipient:

our bodies are made of experiences transformed into physical expression. Because experience is something we incorporate (literally, 'make into a body'), our cells have been instilled with our memories; thus, to receive someone else's cells is to receive their memories at the same time.

(Chopra quoted in Sylvia and Novack, 1997: 221)

Whether cellular memory, genetic composition or pharmaceutical response, all of these explanations reside in the biomedical realm of knowledge about human bodies and are not adequately addressing why particular social characteristics such as gender or of music and food preferences are believed to be transferred. I will return to the idea of social contamination and fully develop it in Chapter 2.

\section{Sociology and phenomenology}

In contrast to Descartes and his body-as-machine legacy, a more complex picture emerges of the relationship between persons (inside their bodies) and their organs when exploring the recipient's experiences of subjectivity alteration post-transplantation. An alternative philosophical theory to Cartesian Dualism emphasises bodily experience as the person being their body that is involved in a perceptive relationship with the external world. This theorising can be found mainly in the work of Maurice Merleau-Ponty, who suggests that the experience of the world is both structured and limited by the body with an emphasis on perception and not Cartesian cognition. For Merleau-Ponty (1945), the relationship between the body and person is closely entwined, and is not separate but interrelated in a harmonious co-existence whereby the body is the sensory gate in and onto the physical world. The main argument in his influential work, The Phenomenology of Perception written in 1945, is that we are our bodies and that our experience of the world is thoroughly embodied (Merleau-Ponty, 2012). He argues that there is no other knowledge than that gained through the living body, and it is through this living of the body that 'I am my body': 
The experience of one's own body, then, is opposed to the reflective movement that disentangles the object from the subject and the subject from the object, and that only gives us thought about the body or the body as an idea, and not the experience of the body or the body in reality.

(Merleau-Ponty, 2012: 205)

Merleau-Ponty views the body as a way of having a presence in the world and is, therefore, the basis of consciousness of being-in-theworld. This 'being-in-the world' is a reversal of Descartes' 'I think therefore I am'. 'Being-in-the-world' is 'I am, therefore I think'. There is nothing to experience if we are not embodied. Embodiment is experience. The focus on perception shows that interaction with the world is an embodied experience that is meaningful and, therefore, perception is more than the physiology of seeing, for example (Crossley, 1995). Csordas suggests 'being-in-the-world' is a term that 'captures precisely the sense of existential immediacy ... in a double sense: ... as a temporally/historically informed sensory presence and engagement ... Being-in-the-world is fundamentally conditional, and hence we must speak of "existence" and "lived experience" (Csordas, 1994: 10). Csordas sets the tone and lays out the importance of the everyday experience of embodiment as one that is culturally laden and socially located, often with a temporal and geographical location:

If embodiment is an existential condition in which the body is the subjective source or intersubjective ground of experience, then studies under the rubric of embodiment are not 'about' the body per se. Instead, they are about culture and experience insofar as these can be understood from the standpoint of bodily being-in-the-world.

(Csordas, 1994: 143)

Embodiment as a socially effected phenomenon also allows discussions of the politics of embodiment. Following Allen-Collinson and Hockey (2011: 332) they suggest a need for a 'sociologised' form of phenomenology which encourages researchers to acknowledge and analyse the 'structurally, politically and ideologicallyinfluenced, historically-specific and socially situated nature of human embodiment and experience' (2011: 332). For example, Cregan shows how the ontology of embodiment (the existence of 
living) and the epistemology of embodiment (of knowing) is shaped by the different social circumstances of, for example, tribalism through to post-modernism (Cregan, 2006). Feminist thinkers such as Judith Butler are concerned with how the body as gendered is constructed by societal norms over time and therefore the embodiment of social ideas around what gender is, for example, are always in process (Butler, 1993). The discussion of subjectivity alteration via organ transplantation is one that is social and culturally entrenched in ideas about embodiment of individuals as well as the embeddedness of people in relationships to each other. Anthropologists such as Sheper-Hughes and Lock produced a key text, The Mindful Body, in the late 1980s which also highlighted how various theoretical constructs of the body were also historically located, such as the phenomenological body, the social and the political body, and indeed the biomedical body (Sheper-Hughes and Lock, 1987). Despite this body of work on how embodiment is sociologically located (and indeed how theories of the body and embodiment are also contextually based), embodiment itself has only recently started to gain increasing recognition. In the first volume and edition of the journal Body and Society, Nick Crossley introduced his thinking on the difference between a sociology of the body and what he calls 'carnal sociology' or what became more widely known as embodiment (Crossley, 1995). Crossley's research draws attention to the importance of relationships with others, an 'intercorporeality'; that is, how the knowledge of a shared bodily bond which links all of us persists (1995). This intercorporeality bond that exists between humans is enriched further by Waskul and Vannini who extend it to include a 'social phenomenology' that locates 'body-self' in intersubjectivity that considers how embodiment is construed from the first-hand experience to being the same for and with, another (2006). Both intercorporeality and intersubjectivity are shown in the research of narratives from organ recipent's narratives as 'people accept that everyday their bodies are inevitably lived alongside and in response to other's bodies' (Lupton 2013: 39). Indeed, the organ donor recipient knows that the organ came from another human being and such intercorporeality is a universal feature. The human response to the organ is one that is related as a certainty based on the universal condition of being human, but simultaneously the 
intersubjectivity and relational element of individuals are seen in the stories told about the organs (or as Parry calls it, the 'social life': Parry, 2018).

A sociologically informed theory of embodiment based on the experience of everyday lives enhances thinking through locating embodiment in social life, structures and relationships. Subjectivity relates to an experience of embodiment that includes the body. A person's experience of their relationship with their body, a connection the word 'embodiment' denotes, is highly ambiguous. Indeed, in the social sciences, embodiment is more generally understood as referring to the flexible and transitory experiences of a person both being body and having a body (Clark, 2007, Crawford, 2014, Cregan, 2006, Crossley, 1995, Crossley, 2001, Farr et al., 2012, Featherstone and Burrows, 1995, Fielding, 1999, Haddow, 2005, Harrison, 2000, Howson, 2004, Howson and Inglis, 2001, Inglis and Howson, 2002, Lupton, 2013, Newman and Carpenter, 2013, Shilling, 2001, Shilling and Mellor, 1996, Smith, 2016, Turner, 1992, Turner, 2008, Waskul and Riet, 2002, Waskul and Vannini, 2006, Weiss, 1999). The experience of both having a body and being a body is as Evans and Lee (2002) point out:

Our bodies serve many purposes and the ambiguity which we as human beings experience as we live in our bodies (as children, mothers, fathers, employees, patients and so on) has to be recognised...an appreciation of ambiguity is central to any understandings of our 'real' bodies

(Evans and Lee, 2002: 12).

Elizabeth Grosz in her book, Volatile Bodies: Towards a Corporeal Feminism, argues too much emphasis is placed on the interiority of the self and not enough attention on the body. Incorporating the model of the Möbius, she argues that the advantage of restructuring our theoretical thinking away from dualisms, of mind/body or subject/object and inside/outside, is the ejection of the 'mind' as having the primary explanatory framework for identity. That is, by no longer locating the self as brain-orientated, theorists and philosophers can make more use of the body. As Grosz argues, male and female bodies are:

incised through 'voluntary' procedures, life-styles, habits and behaviours. Make-up, stilettos, bras, hair sprays, clothing, 
underclothing mark women's bodies, whether black or white, in ways in which hair styles, professional training, personal grooming, gait, posture, body building and sports mark men's.

(Grosz, 1994: 142)

A person is both experientially embodied and socially embedded and therefore subject to the same structural and relational prejudices and beliefs that living in a particular time and place has. As Evans and Lee argued in their edited book Real Bodies regarding race and gender:

In all cases, the social world demands that the body (male or female) meets its expectations about the physical forms of human beings. Becoming male or female is the first complex negotiation for all human beings; the nature of that resolution is then located within a particular set of expectations about race and physical appearance.

(Evans and Lee, 2002: 6)

Becoming masculinised or feminised through organ transplantation is due to how organs are believed to be the same 'sex' as the body they were procured from. In this case, gender is performative on the inside as well as the outside of the body; it is made relevant when discussing organs from men or women. The human body has an inside that retains an integrity element to it. When the skin is breached, and the viscera composition altered and changed, the consequences can also bring to the fore how far-reaching embodiment is in terms of moving inside and beyond the body, affecting and being affected by others.

Varela's account of his liver transplant demonstrates what is known as the Körper/Leib co-existence occurring in the integrity of his own body, through the process of reflection that the ambiguity is grounded within, and the implications the ambiguity of embodiment has for going beyond the individual in the case of organ transplantation:

The feeling of existence, in itself, can be characterized as having a double valence too. This is expressed as a tension between two simultaneous dimensions: embodied and decentred. Embodied: on the one hand examining experience always takes us a step closer to what seems more intimate, more pertinent, or more existentially close. There is here a link between felt quality or the possible depth of experience and the fact that in order to manifest such depth it 
must be addressed with a method in a sustained exploration. It is this methodological gesture which gives the impression of turning 'inwards' or 'excavating'. What it does, instead, is to bring to the fore the organism's embodiment, the inseparable doublet quality of the body as lived and as functional (natural/phenomenal; Leib/Körper). In other words, it is this double aspect that is the source of depth (the roots of embodiment go through the entire body and extend out into the large environment), as well as its intimacy (we are situated thanks to the feeling-tone and affect that places us where we are and of which the body is the place marker). Decentred: on the other hand, experience is also and at the same time permeated with alterity, with a transcendental side, that is, always and already decentred in relation to the individuality of the organism. This defies the habitual move to see mind and consciousness as inside the head/brain, instead of inseparably enfolded with the experience of others, as if the experience of a liver transplant was a private matter. This inescapable intersubjectivity (the 'team') of mental life shapes us through childhood and social life and in the transplantation, experience takes a tangible form as well. But it is also true in the organism's very embodiment, appearing as the depth of space, of the intrinsically extensible nature of its sentience, especially in exploring the lived body.

(Varela, 2001: 262)

The two perspectives (of separation and having a body versus connectedness and being a body) that make up the ambiguity of embodiment are referred to by the philosopher Husserl as the experience of the body as a 'thing' (Körper) or as a lived body (Leib) (Slatman and Widdershoven, 2010). I quote Varela at length because his reflections show that ambiguous embodiment is neither an abstract nor neutral (or even neural) static state. Varela not only dismisses the neural centric approach to subjectivity, but his decentred reference to the multiplicity of identity links the body modification via the integrity of the viscera, the subsequent subjectivity alteration and relationships with other people. That is, individuals are embodied, but as people, they are also embedded within particular social networks and temporalities. Varela's account of transplantation highlights how embodiment is being and having simultaneously, and embodiment is inevitably tied to others:

A person does not 'inhabit' a static object body but is subjectively embodied in a fluid, emergent and negotiated process of being. In this process, body, self and social interaction are interrelated to such 
an extent that distinctions between them are not only permeable and shifting but also actively manipulated and configured. The body (noun) is embodied (verb).

(Waskul and Riet, 2002: 488)

\section{Absent absences, or visible absences?}

Despite the discussion of how embodiment involves the relationship to others as in our intercorporeality (recognition of our biological similarity) and intersubjectivity (the recognition of social variability) it is the ambiguity of embodiment that is relevant in terms of how body modification alters our own subjectivity. It is not a question of whether embodiment is ambiguous but when this ambiguity matters. Generally, it is not a problem as our bodies are mostly absent to us. Leder, inspired by Merleau-Ponty's work but in contrast to it, generally views the body (and therefore embodiment) as a routine absence. Most of the time, our body is an absent experience. If it were a constant presence, it would simply get in the way of routine everyday living. For Leder, the body is all about absence:

Human experience is incarnated. I receive the surrounding world through my eyes, my ears, my hands. The structure of my perceptual organs shapes that which I apprehend. And it is via bodily means that I am capable of responding ... While in one sense the body is the most abiding and inescapable presence in our lives, it is also essentially characterized by absence.

(Leder, 1990: 1)

Drawing on how Leder's approach shows how everyday bodies are generally absent and how such an absence is taken for granted and little reflected upon. Fielding has argued that it is not embodiment that disappears but that it is subdued or quietened in the cognition and over-thinking that is required in daily life (Fielding, 1999). When walking, we are not thinking of the coordinated movements of the legs to work together to walk, nor the facial muscles that allow us to smile or the actions needed to extend our hand out to type these words. In the day-to-day activity, our body is absent to us (a primary absence), and it is only in times that it is challenged 
and tested (or its composition modified by amputation and transplantation) that the body becomes an absent absence; a secondary absence or dys-appearance for Leder. Leder does not draw out the implications of this fluidity between absence and dys-appearance any further nor whether dys-appearance becomes an absence. However, his argument implies embodiment is not a static state and that it fluctuates, making the ambiguity relevant when the circumstances cause an individual to reflect upon it such as the case in limb amputation and indeed organ transplantation.

\section{Amputation and transplantation: visible and invisible absence}

In dys-appearance, the body's absence in everyday life becomes very much a focal point; a 'corporeal self-consciousness' (Leder, 1990: 98). Nevertheless, what happens when parts of the body do become absent in a physical sense? That is, when a limb is amputated? How does this form of absence affect dys-appearance? Merleau-Ponty discusses the example of a 'phantom limb' when a person has undergone amputation and yet still experiences the presence of the limb; he claims that 'The phantom arm is not a representation of the arm, but rather the ambivalent presence of an arm' which is not, he argues, a cognitive assessment of the 'I think' variety, adding it as a critique towards Descartes (MerleauPonty, 2012: 83). Indeed, Sobchack, when giving her account of her leg amputation, highlights how the absence of her limb is an active presence (Sobchack, 2010). Demonstrating that the subjective experiences of amputees are important, Sobchack's account of amputation highlights how the absence of a limb is an active presence (Sobchack, 2010). Her narrative of the limb's continued presence revolves around her lived body experience:

where was my leg? It had objectively disappeared in the hospital ... But it had also subjectively ' $d y s$-appeared', its presence in absence now marked 'here' and 'there', figuring itself in odd ways against the ground of where it once had lived its ordinary form of disappearance, its transparent and enabling absence in presence ... looking at my body stretched out before me as an object, I could see nothing there where my transparently absent leg had been. On the other 
hand, feeling my body subjectively, ... I most certainly experienced 'something here' - the something sort of like my leg, but not exactly coincident with my memory of its subjective weight and length; and the 'here' somewhere in the vicinity my leg had previously occupied, but not exactly coincident.

(Sobchack, 2010: 57 emphases original)

For Sobchack, looking at her body, it is an object and yet feeling it, at the same time, is a subjective experience. Sobchack's account does not seem to dwell in the realm of proprioception as defined as that sixth sense of body awareness. The experience of embodiment for Sobchack is an absent presence, and simultaneously her reflections cause her to conclude the body is both object and subject at the same time and in the same space. Sobchack's discussion of her amputation shows how she experienced her entire body as an object, and in Leder's terms, her body was made 'asunder'. ${ }^{8}$ Before her reflection caused by the amputation, her body is absent, and it is partly due to the reflection that, ironically, causes the duality after that. Only by focusing upon my body now am I immediately aware of it. Both Varela's account of his liver transplantation and Sobchack's of her limb amputation demonstrate how the ambiguity is 'thought into' existence and the split is created from the unity that both precedes and produces it. Gadow argues that although dualism is created by the cognition that reflects on where I am in the body, it makes the question of embodiment even more pressing:

Let us grant for a moment that the critique succeeds in showing that the essence of human existence is embodiment, that the self is inseparable for the body ... Even when we grant this, the problem of the relation between self and body is not solved; it only becomes more interesting. Body and self, although inseparable, are not identical.

(Gadow, 1980: 172)

Making the body's 'absence absent' is creating the separation between body and person that was inseparable before it. As our identity is partly generated through this introspection into our physical condition, it generates the self-knowledge regarding how it is that we are embodied. Returning to Sobchack's narration about her amputation, while the leg is no longer there, it has a presence in experiential terms, despite its undeniable physical absence. 


\section{Descartes is dead - long live Descartes!}

The problem of the mind and body split born out of Cartesian Dualism is one that has been struggled with and dismissed by philosophers and sociologists who accept a dual-existence of both having and being (Ozawa-De Silva, 2002). Cartesian Dualism is not dead as it harbours within it the very connection that presupposes the duality. The connection that presupposes reflection keeps Cartesian Dualism alive. Most experience suggests the cognition is an activity that takes part in the brain. Madison argues before it is possible to treat the body as a 'thing' or an 'object' (as Descartes would have it), the body must exist, as a condition of existence. In other words, for the body to be separated from the person via reflection of the self, the person and their body are intertwined in the first instance (Madison, 1981). That a person can reflect on the nature of the self and body (as Descartes had shown), but at the same time it is the reflection that shows the separation between body and person as the body becomes an active presence. A person has to be a body in the first instance for the body to become separate to the person through, for example, reflection or focusing. Pre-reflection implies that the body is the person, and at the pre-reflexive level, we are a body and embodied (Jenkins, 2013). This is a subjective element to explore that Descartes, through his introspection, attempted to think through. He equated the result, the separation of mind and body, to the process of his reflections. Cartesian Dualism implies that there is no separation, without there being a unity, from which the separation can emerge.

\section{Conclusion: Triad of I - identity, image and integrity}

The view of the Cartesian body-as-machine is one that is arguably found in all areas of society and not just in the medical world. It is uncontroversial to say that in the current neuro-culture, our understanding of our bodies are that of objects. We have a body in the same way that we may own and drive a vehicle. It seems that 'I think therefore I am' is deeply rooted in Western society as it is a collective experience to feel 'I' as somehow situated in the place where cognition occurs in the brain. However, a different ideology 
also persists that focuses on the body as the person and is in contrast to the Cartesian Dualism that emphasises a body is a machine. The persistence of stories that transplantation, or limb loss, causes subjectivity alterations suggest a more integrated view of body and subjectivity than the medical model of the body would allow. Philosophically, phenomenologists such as Merleau-Ponty highlight how a person and the body are the same, and that 'I am' comes before 'I think'. The conditions for duality and of 'I think therefore I am' are based on a position of unification in the first place. Hence, the experience of being and having a body are simultaneously possible and are not necessarily in conflict with each other. I have argued further that this is not just a philosophical issue but a sociological one, as the modern practices of organ transplanation have thrown the ambiguity into sharp relief.

Organ transplant recipients have reported subjectivity alterations that are often associated with gender. Explaining how this can happen has involved, first, demonstrating that an organ from a human donor can contaminate the recipient with characteristics (that is, through social or cellular means or both). Second, that breaching the body boundaries is a transgression and is 'when' the ambiguity of embodiment is focused upon by the recipient. It throws up the question as to whether the person is a body or whether the person has a body. The ambiguity that was previously unimportant is no longer absent. Modifications such as an organ gain or a limb loss create a body (that has an interior as well as an image) whose 'absence' is no longer 'absent'. The experience of embodiment is brought into a 'corporeal self-consciousness' or the 'dys-appearance' as Leder describes it (1990) when a bodily modification such as transplantation or amputation occurs.

Our visible and invisible bodies are mostly absent to us; we do not focus upon our legs working in the same way that we are unaware of our heart beating or kidney's functioning. When that 'absence becomes absent' the dys-appearance makes the body's previous absence absent throwing into sharp relief how the experience of embodiment is ambiguous. This is the case whether it is an amputation or transplantation, whether the modification occurs on the inside (integrity) and out (image) and both are linked to identity.

The narratives from organ transplant recipients show that body modification to the inside of the body can cause subjectivity 
alterations, suggestive that the inside or the integrity of the body is vital to a person's sense of identity. Indeed, integrity has recently come to be seen as important in the area of body studies (cf. (Blackman, 2010, Shildrick, 2010, Sobchack, 2010). In Latin origins of 'integer' mean whole, complete and intact (Slatman and Widdershoven, 2010: 70) and this expresses the unity of organs within the body. This body then is part of our identity, with an integrity and image that is the 'Triad of I'. Thus, an embodiment is required that reckons on the 'outside-in' as well as the 'inside-out'. So how can the inside-out (integrity) also be outside-in (image)? This is not just an 'inside-out' experience but an 'outside-in' one. Embodiment is not just about the experience of isolated individuals, and although a person is ambiguously embodied (inside-out), people are embedded in particular environments which include relationships and interactions with others (outside-in). Organ transplantation and amputation demonstrate how porous and fluid meanings are in terms of individual embodiment that is also socially embedded when organs are taken from one individual and placed in another. There is not a static embodiment but a continual flow in the Triad of I and with others. The importance of others has to be stressed because the way that the body is configured relationally is needed. The ambiguity of embodiment becomes the focus when dys-appearance is caused by breaching the integrity of the body. Embodied individuals are embedded in social contexts, and others attach meanings to bodies, but how are other bodies that are not human constructed in diverse ways? If human recipients take on human characteristics through organ transplantation from others, would subjectivity also alter if non-human animal organs or a mechanical device are implanted? If this is the case, what more can be learned about ambiguous embodiment and the Triad of I?

\section{Notes}

1 As discussed in the introduction, I avoid using the word self. I also use subjectivity interchangeably with identity, but prefer subjectivity as it alludes to the more diffuse elements of the personal that makes it more often experiential and relational. 
2 Her death in 2016 aged 49 years was said to have been caused by cancer.

3 www.theguardian.com/world/2007/oct/05/france.international? CMP=aff_1432\&awc=5795_1548238741_28f7129530f66604f4ac2 $0 \mathrm{dc} 75 \mathrm{ba} 7 \mathrm{~d} 3 \mathrm{c}$ (accessed January 2020).

4 When Louis died, the heart was removed as it was required by South African police and as Denise had died in a car accident, thus 'the heart ... was an important part of two different people with separate histories' (Nathoo, 2007).

5 The ethical discussions around the Harvard Committee's decision in 1968 to redefine death as brain death coincided with the first organ heart transplant. As Peter Singer commented: 'All living things eventually die and we can generally tell when they are alive and when they are dead. Isn't the distinction between life and death so basic that what counts as dead for a human being also counts as dead for a dog, a parrot, a prawn, an oyster, an oak, or a cabbage? ... Brain death is only for humans. Isn't it odd that for a human being to die requires a different concept of death from that which we apply to other living beings?' (Singer, 1994: 25).

6 Yet my own earlier research has shown that some donor families deny an immortality reason and draw parallels with replacing parts of the car and is a view of individuals' bodies that can also be found in donor family accounts of why they donated (Haddow, 2005).

7 Accessed October 2015: http://odt.nhs.uk/transplantation/recipientcoordination/donor-family-and-recipient-contact/.

8 By making the body 'asunder' suggests Leder has more in common with Descartes than might first be appreciated, for example, regarding the separation (dys-appearance) of the body and Cartesian Dualism where a separation also occurs. 